\title{
CONGENITAL EXTRAOCULAR MUSCULAR DEFECTS
}

\author{
J. P. LEE \\ London
}

Congenital defects of the extra-ocular muscles excluding the levator are not common but may cause a variety of types of incomitant strabismus. The aetiology is in many cases obscure and the management may present problems.

\section{ABSENCE OF AN EXTRA-OCULAR MUSCLE}

Duke Elder ${ }^{1}$ quotes a number of references to cases of absence or hypoplasia of any of the extra-ocular muscles, many of the references dating from the 19th Century. My personal experience of absence of extra-ocular muscles is limited to two main clinical situations, craniofacial dysostosis and congenital superior oblique palsy. An adult case of Crouzon's syndrome had a vestigial inferior rectus and inferior oblique on both sides with a consequent gross hypertropia and deficient ocular depression. In contrast to this was a child of six years with Apert's syndrome who had a bilateral hypotropia and esotropia with an A pattern and who at surgical exploration turned out to have almost completely undeveloped superior rectus and superior oblique muscles on both eyes.

Helveston has pointed out the very high incidence of anatomical abnormalities in congenital superior oblique palsy, reporting on a series of cases with congenital absence of the superior oblique tendon ${ }^{2}$ and more recently describing his classification of superior oblique palsy based on likely clinico-pathological associations. ${ }^{3}$ I have seen some five patients who at surgery for an attempted superior oblique plication had an either absent or practically non-existent superior oblique tendon and who required alternative surgical strategies to get a good result. I suspect this abnormality is even more common than reported as many surgeons do not perform superior oblique plication as a primary procedure.

\section{ABNORMALITIES OF MUSCULAR INSERTIONS}

Muscle insertions have been reported to have been abnormally anterior or posterior to the normal position and many surgeons have reported cases of patients who

Correspondence to: John P. Lee, FRCS FCOphth., Moorfields Eye Hospital, City Road, London EC1V 2PD had secondary or extended scleral attachments posterior to the true insertion. The superior oblique, as reported by Helveston, ${ }^{3}$ may be found to insert on the nasal side of the superior rectus or may insert directly into the Tenon's fascia without actually attaching to the sclera.

Fink in his communications of 1947 and $1962^{4,5}$ showed that there was a very wide variation in the insertions of the inferior and superior oblique muscles in a series of cadaver eyes.

\section{ABNORMALITY OF MUSCULAR ORIGIN}

Little has been written about this matter possibly because most of the extra-ocular muscles take origin from the apex of the orbit and it is not normally the province of the strabismus surgeon to describe abnormalities in that area. However, the inferior oblique, which arises from the anterior part of the orbit has been shown by Whitnall ${ }^{6}$ to have wide variation in its origin although little is known regarding the other extra ocular muscles.

\begin{abstract}
ABNORMAL LINE OF MUSCULAR ACTION
It is well known that in the craniofacial syndromes there may be very marked abnormalities of the line of action of horizontal rectus muscles and this point has been made repeatedly in literature regarding these conditions. In plagiocephaly the trochlea may be further back on the affected side than the other and this may lead to a relative superior oblique 'palsy' due to greater mechanical action on one side than the other. Fink in $1962,{ }^{5}$ followed by Gobin in $1969^{7}$ pointed out that difference in the angles of insertion of the superior and inferior obliques on the eyes could lead to the causation of A and V patterns of strabismus and both authors suggested that re-positioning of oblique muscle insertions might be appropriate management for these problems.
\end{abstract}

\section{MULTIPLE INSERTIONS}

Emmel et al., ${ }^{8}$ described a series of 200 cadaver eyes in which a bifid or trifid insertion of the inferior oblique was shown in 50\% of cases. This study was of interest as previously it had been suggested that if such insertions were found at the time of surgery, this represented an artefact 
due to faulty surgical technique, but this paper showed quite clearly that this was a true anatomical abnormality. Similarly, others have described double insertions of the medial and inferior rectus muscles.

\section{PRESENCE OF AN ABNORMAL OR ATAVISTIC MUSCLE}

A number of authors have pointed out that in vertebrates, there is a retractor bulbi muscle derived from the same embryonal tissue mass as the other extraocular muscles. Among mammals this is particularly prominent in rodents, ungulates and sirenians, but absent in primates. Supply is by the sixth cranial nerve in most species. Whitnall ${ }^{9}$ has described a case of marked persistence of this muscle in which part of the muscle was supplied by the sixth cranial nerve and part by the third cranial nerve. More recently Muhlendyck in $1991{ }^{10}$ has suggested, in a pair of case reports, that persistence of a retractor bulbi muscle might represent a possible cause of a Duane's syndrome. It is quite possible that remnants of this muscle have accounted for some of the other musculofascial abnormalities described by other authors but little is known of its likely incidence or frequency.

\section{TENDINOUS OR FASCIAL ABNORMALITY}

Under this heading one could classify strabismus fixus and Brown's syndrome. Strabismus fixus is a typically unilateral but occasionally bilateral condition in which the affected eye is grossly convergent and often hypotropic. Surgical management may be extraordinarily difficult and may require the use of free tenotomy to detach the abnormal muscles from the globe.

Often even this manoeuvre still leaves the eye with a residual deviation suggesting that there is a generalised abnormality of the orbital fascia and not simply a fibrotic contracture of an individual muscle.

Brown's syndrome ${ }^{11}$ is well known to most ophthalmologists. The features are:

(a) limitation of elevation in adduction,

(b) down drift on adduction,

(c) over-action of the contralateral superior rectus muscle,

(d) an abnormal head posture,

(e) a positive traction test

(f) occasional bilaterality.

The aetiology is obscure, it has been suggested that there may be a short superior oblique tendon and that the tendon may have a thickening or lumpiness, causing it to pass poorly through the trochlea. It has been suggested that the trochlea itself may be abnormal and the possibility of paradoxical innervation has been repeatedly raised, although without much supporting evidence.

\section{MUSCULAR FIBROSIS}

Under this heading is classified the rather diffuse collection of disorders sometimes known as progressive fibrosis syndrome, general fibrosis syndrome, congenital external ophthalmoplegia or the shallow A syndrome. These are all probably versions of the same thing and have certain features in common.
The patients show congenital bilateral ptosis, and asymmetric hypotropia with grossly limited elevation of both eyes, and convergence of the eyes on attempted elevation. In addition there is almost invariably amblyopia of the non-preferred eye and an abnormal head posture in order to fix with the preferred eye. Marked astigmatic refractive errors are the rule and many cases have a strongly familial tendency in which the inheritance is of the autosomal dominant variety.

A good deal of speculation has occurred as to whether these patients have a primarily muscular abnormality or whether this is a secondary change in muscles following a form of progressive neurological degeneration. At present it is difficult to be sure which of these two views is the more convincing.

Management of these children is not easy. It is important to refract them which may not be easy as to get 'onaxis' and retinoscope their eyes with accuracy can involve considerable difficulty in view of their very marked hypotropic and sometimes exotropic ocular position. For the same reason fitting them with glasses can often be a technically testing task. They require occlusion for their amblyopia and this may be difficult as the child may require to adopt a very marked head posture when fixing with its less preferred eye and this is usually cosmetically worse than the head posture fixing with the preferred eye. Surgery can be undertaken and Boergen ${ }^{12}$ has recently reported a large series in whom an aggressive surgical approach led to good clinical results. Ptosis surgery is certainly possible and one often finds that other family members have had ptosis surgery. These patients seem remarkably resistant to corneal exposure and may do well with frontalis suspension procedures.

\section{PARADOXICAL INNERVATION}

There are a number of unusual conditions not infrequently found in association, including Duane's syndrome, the Marcus-Gunn jaw-winking syndrome, the crocodile tear syndrome and other similar bizarre synkineses.

Despite the many classifications suggested for Duane's syndrome, I find it most useful to divide cases into typical and atypical. Typically the eye will show limitation of abduction with widening of the palpebral aperture on attempted abduction, retraction of the globe on adduction and narrowing of the palpebral aperture secondary to the retraction. Atypical features include variable degrees of limitation of adduction and up- or down-shoots of the affected eye on attempted adduction or abduction. In addition some degree of bilaterality is much more common than is generally realised, and careful inspection of the other eye will often show some limitation of abduction.

Suggested aetiologies include contracted and fibrotic lateral rectus muscles, or, more popularly, paradoxical anomalous innervation of the horizontal recti. It has been suggested by a number of authors ${ }^{12,13,14}$ that there has been agenesis of the sixth nerve nucleus with replacement of its nerve supply with supply by the third nerve to the lateral rectus muscle. 
We have recently completed an electromyographic investigation of Duane's retraction syndrome at Moorfields Eye Hospital with some preliminary results. To date we have examined six adults with left-sided Duane's syndrome, four of them being of the type one variety and two being type three. The age range was between 18 and 45 years, three were female and three were male. The purpose of the study was to perform diagnostic electromyography prior to Botulinum Toxin injection with a view to assessing the likely outcome of surgery. White and Lee ${ }^{15}$ recently presented at the International Orthoptic Association Congress experience with this agent as a predictor of surgical outcome in this condition.

The final results will be reported in due course, but in brief our findings were broadly similar to those reported by Huber ${ }^{12}$ and others.

Of our lateral recti, five out of six were silent on both adduction and abduction, and one out of six showed firing on both adduction and abduction.

Features of this study, however, which are unusual involve two cases who showed abnormal firing of the medial rectus on their second electromyogram which was not present on the first EMG. We speculate that this might be due to differences to electrode placement suggesting that different parts of the same muscle had different nerve supplies. This possibility had been discussed by Huber previously. Although it is possible that this was some kind of effect of Botulinum Toxin it is hard to understand how that could cause difference in actual innervational patterns of muscles rather than simply electrical silence.

The other interesting finding was of the case of a 32 year old woman with a very marked hyper-deviation increasing dramatically on adduction in association with globe retraction. She showed a clear increase in inferior oblique firing on adduction but no significant increase in firing in the superior rectus muscle.

\section{CONCLUSION}

Congenital muscular defects occur but they are in general unusual causes of strabismus. They are probably underreported and many of them have been the subject of simple case history studies. Perhaps a carefully conducted series of cadaver dissections might give a clearer idea as to the true prevalence of these interesting and unusual anomalies.

\section{REFERENCES}

1. Duke-Elder, S. System of Ophthalmology. Vol.III, part 2, 977-996 and Vol VI, 736-752. pub. H.Kimpton. 1973.

2. Helveston EM, Giangiacomo JG, Ellis FD. Congenital absence of the superior oblique tendon. Trans. Am. Ophthalmol. Soc. 1981, 79: 123-135.

3. Helveston EM. Classification for superior oblique palsy. New Orleans Acad. Ophthalmol. Symp. 1990. ed. Haik, pub SLACK incl.

4. Fink WH. Trans. Am. Ophthalmol Soc. 1947, 52: 500.

5. Fink WH. Surgery of the vertical muscles of the eye. 2 nd ed. 1962.

6. Whitnall SE. Anatomy of the human orbit 1921.

7. Gobin MH. Sagittalization of the oblique muscles as possible cause for the 'A', ' $\mathrm{V}$ ' and ' $\mathrm{X}$ ' phenomena. Br. J. Ophthalmol 1968, 52: 13-18.

8. Emmel DK, Apt L, Foos R. in 'Strabismus', Proceedings of the International Strabismological Association, ed Reinecke 1982. 669-673.

9. Whitnall SE. J. Anat. Physiol. 1911, 46: 36.

10. Muhlendyck H. Proceedings of 19th European Strabismological Association. ed Kaufman 1991 (in press).

11. Brown HW. Strabismus Ophthalmic Symposium I.ed Allen. St Louis 1950, 205.

12. Boergen P. Proceedings of 18th European Strabismological Association. ed Kaufman 1989 55-9.

13. Huber A. Electrophysiology of the retraction syndromes. Br. J. Ophthalmol 1974, 58: 293-300.

14. Hotchkiss MG, Miller NR, Clark AW, Green WR. Bilateral Duane's syndrome. A clinico-pathological case report. Arch. Ophthalmol, 1980. 98: 870-4.

15. Miller NR. Unilateral Duane's retraction syndrome (Type I). Arch. Ophthalmol. 1982, 100: 1468-72.

16. White JS, and Lee JP. The diagnostic use of botulinum toxin in Duane's syndrome in 'Advances in Amblyopia and Strabismus', Proceedings of 7th International Orthoptic Congress, ed Tillotson 1991. 341-345. 